\title{
Bench Scale Treatability Studies of Contaminated Soil Using Soil Washing Technique
}

\author{
M. K. GUPTA*, R. K. SRIVASTAVA ${ }^{\S}$ and A. K. SINGH \\ * Department of Civil Engineering, \\ Kamla Nehru Institute of Technology, \\ Sultanpur (Uttar Pradesh)- 228118, India. \\ ${ }^{\S}$ Department of Civil Engineering, \\ Motilal Nehru National Institute of Technology, \\ Allahabad (Uttar Pradesh)- 211004, India. \\ Department of Applied Sciences, \\ Kamla Nehru Institute of Technology, \\ Sultanpur (Uttar Pradesh) 228118, India. \\ mohitgupta0311@gmail.com
}

Received 12 May 2009; Accepted 5 July 2009

\begin{abstract}
Soil contamination is one of the most widespread and serious environmental problems confronting both the industrialized as well as developing nations like India. Different contaminants have different physicochemical properties, which influence the geochemical reactions induced in the soils and may bring about changes in their engineering and environmental behaviour. Several technologies exist for the remediation of contaminated soil and water. In the present study soil washing technique using plain water with surfactants as an enhancer was used to study the remediation of soil contaminated with (i) an organic contaminant (engine lubricant oil) and (ii) an inorganic contaminant (heavy metal). The lubricant engine oil was used at different percentages (by dry weight of the soil) to artificially contaminate the soil. It was found that geotechnical properties of the soil underwent large modifications on account of mixing with the lubricant oil. The sorption experiments were conducted with cadmium metal in aqueous medium at different initial concentration of the metal and at varying $\mathrm{pH}$ values of the sorbing medium. For the remediation of contaminated soil matrices, a nonionic surfactant was used for the restoration of geotechnical properties of lubricant oil contaminated soil samples, whereas an anionic surfactant was employed to desorb cadmium from the contaminated soil matrix. The surfactant in case of soil contaminated with the lubricant oil was able to restore properties to an extent of $98 \%$ vis-à-vis the virgin soil, while up to $54 \%$ cadmium was desorbed from the contaminated soil matrix in surfactant aided desorption experiments.
\end{abstract}

Keywords: Contamination, Remediation, Sorption, Desorption, Surfactant, Soil Washing. 


\section{Introduction}

Soils and groundwater may be contaminated directly by infiltration of leachate from land disposal of both sold and liquid wastes, waste leachates and leaks from industrial metal processing facilities; petroleum leaks and spills from refineries, manufacturing sites, power plants, distribution depots, and retail service stations ${ }^{1}$. A variety of geophysical and geochemical reactions including sorption or ion exchange, oxidation/reduction, precipitation/dissolution influence the mobility and speciation of contaminants in soil and groundwater ${ }^{2}$. While precipitation, sorption (adsorption) and ion exchange reactions can retard the movement of contaminants through subsurface medium, the rate and extent of these reactions, on the other hand, depend on such factors as $\mathrm{pH}$, complexation with other dissolved constituents, exchange capacity of the geological materials and organic matter content.

A range of technologies are available for the remediation of contaminated soil and groundwater. General approaches to the remediation include isolation, immobilization, toxicity reduction, physical separation and extraction. These approaches can be used for many types of contaminants but the specific technology selected for contaminated soil will depend on the type and form of contamination and other site specific characteristics. One or more of these approaches can be combined for more cost-effective treatment. A number of the available technologies have been demonstrated in full-scale application and are presently commercially available ${ }^{3}$.

Surfactant washing is an ex situ process; the possible configurations include excavation of contaminated matrix, heaping on the plastic liners or other impermeable barriers and irrigating the piles of contaminated material with washing solutions such as surfactant. Batch washing of the contaminated soil in tanks or lined pits, and continuous flows washing in counter current or normal modes are other techniques employed ${ }^{3}$. In situ surfactant flushing, on the other hand, involves the delivery of surfactant solution to the contaminated medium by irrigation and/or injection wells. The contaminant laden surfactant solution is pumped out through recovery wells.

To understand the working of these techniques, one must understand the principles of surfactant solution behaviour. Surface active agents or surfactants are the chemical compounds that have the potential to alter the properties of fluid interfaces. They are main ingredients of such commercial and industrial products as, soap, detergent, wetting agent, dispersant, emulsifier, foaming agent, corrosion inhibitor, antistatic agent etc. Although the use of surfactants to remediate contaminants in the subsurface is a relatively new area of application, their use in subsurface systems dates back to 1963 when petroleum sulfonates were patented for widespread use in enhanced oil recovery efforts ${ }^{4,5}$.

A surfactant works as a remediation tool by lowering the contaminant-water interfacial tension and thereby causing a degree of contaminant mobility, and enhanced contaminant solubility in water. The surfactant molecule is typically composed of a strongly hydrophilic (polar, water-loving) group, or moiety and a strongly hydrophobic (apolar, water fearing) moiety ${ }^{6,7}$. The entire surfactant monomer is often referred to as amphiphilic (both loving) because the polar group has a large affinity for polar solvents, such as water, whereas nonpolar group has a great affinity for non-polar or hydrophobic solvents, which include most organic contaminants. The hydrophilic 'head' group often includes anions or cations such as sodium, chloride, or bromide. Hydrophobic portions or 'tails' are usually hydrocarbon chains typically containing 12 or more carbon atoms. 
When a sufficient amount of surfactant is added to an aqueous solution, aggregation of surfactant monomers referred to as micelles begins. Micelles are often spherical in shape and can contain hundreds of surfactant monomers. In these aggregates or micelles, the hydrophobic groups fill the core and the polar groups are in contact with aqueous phase water molecules. Typical micelles contain 50 to 100 surfactant molecules or monomers. The micelle formation is surfactant concentration dependent. The threshold concentration at which micelles begin to form is termed as critical micelle concentration (CMC); below CMC virtually no micelles can exist.

A micelle is formed with hydrophobic tails of surfactant monomers in the interior, away from the water, while the hydrophilic heads are on the surface. Each micelle therefore has at its interior a very tiny droplet of non-polar hydrocarbon phase. This non-polar phase is able to dissolve relatively non-polar solutes (hydrophobic compounds) such as PCBs, organic solvents, chlorinated pesticides and the like. This phenomenon is known as micellar solubilisation and is responsible for increasing the solubility of hydrophobic compounds by several times in water. The solubility of these hydrophobic compounds in water is quite small, e.g., of the order of $1 \mathrm{mg} / \mathrm{L}$ for PCBs. In surfactant solutions, on the other hand, their solubility is increased manifold, perhaps 100-1000 times, by micellar solubilization.

\section{Experimental}

Local alluvial soil obtained from open excavations at approximately one meter depth below the ground level was used for the experimental work. Physical and chemical properties of soils relevant to the experimental work were determined as per the appropriate IS codes. The soil as per IS 1498 (1970) has been classified as CH (clay of high compressibility).

For the sorption experiments, stock standard of sorbate solution was prepared from analytical reagent grade high purity cadmium metal. For the above mentioned purpose $1.00 \mathrm{~g}$ of cadmium metal was dissolved in $20 \mathrm{~mL}$ of $1: 1 \mathrm{HNO}_{3}$ and diluted with deionized water to $1000 \mathrm{~mL}$ to give stock concentration of $1.00 \mathrm{~mL}=1.00 \mathrm{mg}$ cadmium. The solutions of the required strength for the sorption experiments were prepared from the stock solution. The sorption experiments were performed in a rotary shaker at $15-20 \mathrm{rpm}$ using $300 \mathrm{~mL}$ stopcorked bottles containing $250 \mathrm{~mL}$ of cadmium solution and $2.5 \mathrm{~g}$ soil (fraction finer than 425 $\mu$ ) with solids-solution ratio of about 100 . Initial $\mathrm{pH}$ of the sorbate (metal solution) was adjusted for the each set of experiment by adding $0.1 \mathrm{M} \mathrm{HCl}$ or $0.1 \mathrm{M} \mathrm{NaOH}$. Each bottle was labeled with initial concentration of solute (e.g., 50, 100, 150, 200 and $250 \mathrm{mg} / \mathrm{L})$, initial pH (e.g., $3,4,5,6,7,8)$ and time duration of sorption i.e., 15, 30, 60 minutes, 2, 4, 8, 16 hours. The partly desorbed sorbate corresponding to a particular initial concentration, initial $\mathrm{pH}$ and time interval was removed from the rotary shaker, centrifuged for at least 5 minutes at $500 \mathrm{rpm}$ and thereafter vacuum filtered to separate out the soil particles. The filtrate was used to determine the residual metal in the sorbate solution by flame atomic absorption spectrophotometer (Model: Perkin Elmer 3100). For desorption experiments, the contaminated soil sample corresponding to sorbate concentration of $100 \mathrm{mg} / \mathrm{L}$ and $\mathrm{pH}=6$ was used. Acidic soil environment favors heavy metal solubility and thereby desorption, therefore most heavy metal remediation studies using surfactants have employed acidic conditions. Several mechanisms have been suggested as to how surfactants along with alkali or acid solutions enhance metal leaching; ion exchange, electrostatic interaction and solubilization ${ }^{8,9}$. Surfactant sodiumlauryl sulphate (SDS) at $1 \%, 2 \%$ and $3 \%$ was therefore used, employing the same experimental procedure as in the sorption experiments. The amount of metal sorbed or desorbed by the soil was calculated from the initial metal concentration of the solution and metal content of the supernatant after the specified period of shaking using the following equation ${ }^{10}$. 


$$
Q=\left(C_{o}-C_{e}\right) * \frac{V}{M}
$$

Where $\mathrm{Q}$ is the metal uptake or sorption/desorption $(\mathrm{mg} / \mathrm{g})$ for the specified period, $\mathrm{C}_{\mathrm{o}}$ and $\mathrm{C}_{\mathrm{e}}$ are the initial and equilibrium metal concentrations in the solution $(\mathrm{mg} / \mathrm{L})$, respectively. $\mathrm{V}$ and $\mathrm{M}$ respectively are the volume of solution $(250 \mathrm{~mL})$ and mass of sorbent $(10 \mathrm{~g} / \mathrm{L})$.

For the contamination of soil with the organic contaminant, a popular lubricant engine oil (Castrol CRB $20 \mathrm{w} / 40$, density: $8.28 \mathrm{kN} / \mathrm{m}^{3}$ ) was chosen. The required quantity of ovendried, cooled and pulverized soil was mixed with $4 \%$ and $6 \%$ of the lubricating oil by dry weights (e.g., for a $4 \%$ mix, $40 \mathrm{~g}$ of oil was mixed with one $\mathrm{kg}$ of the dry soil). For the above-mentioned purpose, about $8 \mathrm{~kg}$ of soil was sprinkled with the required quantity of oil (for every mix); the contents were vigorously mixed with hands for sufficient time in order to break the lumps and then placed in covered containers for saturation for a week's time. It has been reported in the literature ${ }^{11}$ that one week time is sufficient for organic contaminants such as petroleum hydrocarbons to come to equilibrium with the dry soils. During the saturation period, care was taken to break any lumps formed. The uncontaminated soil and various contaminated mixes have been designated as $\mathrm{CH}-1$ and $\mathrm{CH}-2$ (suffix 1 and 2 respectively stand for the virgin or uncontaminated, and $4 \%$ and $6 \%$ contamination with lubricating oil).

The optimum moisture content (OMC) and maximum dry density (MDD) of the virgin (clean) soils as well their mixes with the contaminant were first determined by light compaction tests as per IS: $2720^{12}$. The geotechnical properties of the soil in its virgin state and also those of all the soil-contaminant mixes were then determined on samples remoulded at their respective optimum moisture content (saturated condition, wherever required) and maximum dry density.

The remediation of oil contaminated soil was done using Triton X-100, a non-ionic surfactant under laboratory controlled conditions. Contaminated soil mix was mixed in plain water containing required quantity of surfactant; the ratio of contaminated soil mix and the surfactant was kept constant at 1:4 (w/w). The surfactant quantity was taken as $0.4 \%(\mathrm{v} / \mathrm{v})$, i.e., $4.0 \mathrm{~mL}$ surfactant was used in a liter of water. Nearly 1 to 2 minutes of quick stirring for the dispersion of soil into surfactant was followed by gentle stirring to bring about good contact between soil particles and surfactant solution. Mixture was then stood for about $24 \mathrm{~h}$ for the surfactant to take effect and also to allow fine particles to settle. The oil-laden Surfactant solution was thereafter decanted carefully so that the fine particles do not wash out. The soil was subsequently washed two times with plain water and after the each washing cycle the soil-water suspension was again stood for 24 $\mathrm{h}$ to allow the fines to settle. Finally the decanted soil slurry was kept for air-drying and then oven dried until the moisture in the soil was constant. Optimum moisture content and maximum dry density were first determined for each decontaminated mix by light compaction test. Geotechnical properties for all the decontaminated mixes were separately determined on soil samples remolded at their respective OMC (saturated, wherever required) and MDD.

\section{Results and Discussion}

The physical and chemical properties of the soil used in experimental work are presented in Table 1(a) and Table 1(b). 
Table 1(a). Physical properties of the virgin soil.

\begin{tabular}{lcc}
\hline Clay Size & $<0.002 \mathrm{~mm}$ & $27.0 \%$ \\
Silt size & $0.002 \mathrm{~mm}-0.075 \mathrm{~mm}$ & $70.0 \%$ \\
Sand Size & $0.075 \mathrm{~mm}-4.75 \mathrm{~mm}$ & $3.0 \%$ \\
Specific Gravity & $\mathrm{G}_{\mathrm{s}}$ & $2.64 \%$ \\
Liquid Limit & $\mathrm{w}_{L}$ & 60 \\
Plastic Limit & $\mathrm{w}_{P}$ & $27 \%$ \\
Shrinkage Limit & $\mathrm{w}_{S}$ & $12 \%$ \\
Plasticity Index & $\mathrm{I}_{P}$ & $33 \%$ \\
Activity & $\mathrm{A}$ & 1.22 \\
\hline
\end{tabular}

Table 1(b). Chemical properties of the virgin soil.

\begin{tabular}{cc}
\hline $\mathrm{pH}$ & 7.80 \\
\hline Organic Matter Content, \% & 2.25 \\
Cation Exchange Capacity, meq/100 g & 17.38 \\
\hline
\end{tabular}

The results of sorption experiments at different initial metal concentration and sorbate $\mathrm{pH}=6$ are presented graphically (Figure 1) as relationship between shaking (agitation) time and cadmium remaining in sorbate solution.

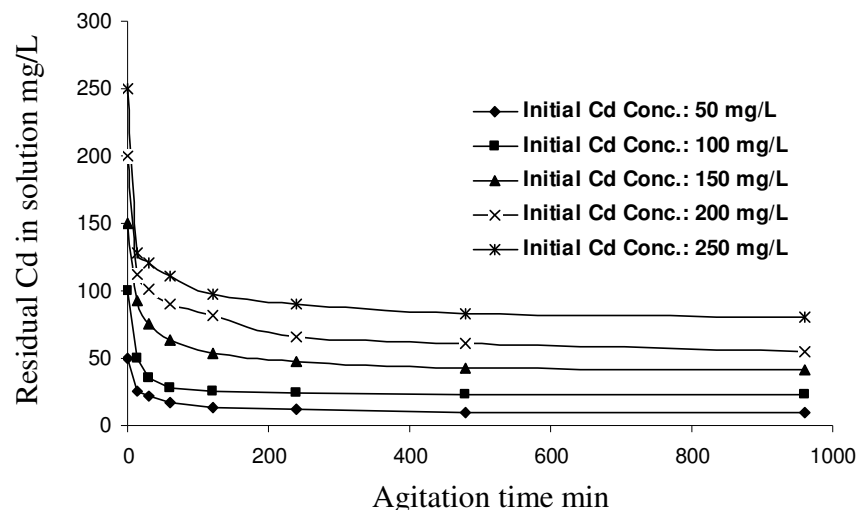

Figure 1. Residual cadmium in solution at $\mathrm{pH} 6$

Sorption of cadmium by the sorbent was very fast at the initial stage of the experiment followed by a slow reaction; with most of the sorption having taken place in the first two hours. Such two-step sorption kinetics has been reported for apparent adsorption of trace metals on clays and metal oxides and hydroxides by several investigators $^{13,14}$. The sorption characteristic displayed by the soil is typical $L$-type sorption behaviour, which is commonly observed for metal sorption by soils 5 . The initial fast sorption rate may be attributed to the readily available external surface sites, while the slow reaction rate corresponds to sorption onto less accessible sites and is controlled by diffusion of the metal into the sorbing phase.

Desorption experiments were conducted in a similar manner as the sorption experiments. Contaminated soil sample corresponding to $100 \mathrm{mg} / \mathrm{L}$ initial cadmium concentration and $\mathrm{pH}=6$ was separately desorbed in aqueous (deionized) surfactant solution strengths of $1 \%, 2 \%$ and $3 \%(\mathrm{v} / \mathrm{v})$. The initial $\mathrm{pH}$ of desorbing medium was kept at 6 . The results of cadmium desorption in surfactant solutions are graphically shown through Figure 2. 


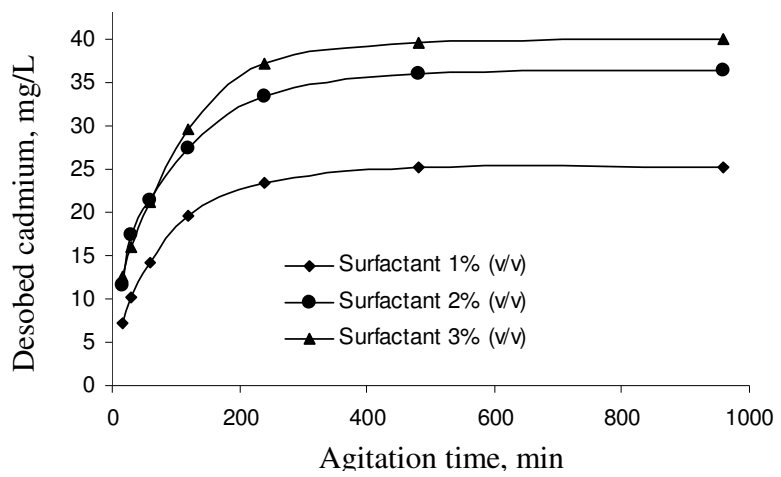

Figure 2. Cadmium desorbed in surfactant solution sorbate strength $=100 \mathrm{mg} / \mathrm{L} ; \mathrm{pH}=6$

Desorption data plot typical inverted $L$ - shape curves and follow the same pattern as the sorption process; with the only difference that desorption took a little longer to reach equilibrium plateau in comparison to the sorption process. Desorption was $34 \%$ at $1 \%$ surfactant concentration; $49 \%$ at $2 \%$ surfactant concentration and $54 \%$ at $3 \%$ surfactant concentration. Most of the cadmium desorbed in the first three hours of the desorption process. Surfactant at $2 \%$ concentration gave the best results as there was only a nominal increase in desorption at the concentration of $3 \%$.

In the Table 2 a summary of the effect of lubricant oil on soil properties after contamination with lubricant oil is presented.

Table 2. Comparison of properties of virgin, contaminated and decontaminated soil.

\begin{tabular}{|c|c|c|c|c|c|}
\hline \multirow[t]{2}{*}{ Property } & Virgin & \multicolumn{2}{|c|}{$\begin{array}{l}\text { Contaminated } \\
\text { Soil }\end{array}$} & \multicolumn{2}{|c|}{$\begin{array}{l}\text { Decontaminated } \\
\text { Soil }\end{array}$} \\
\hline & Soil & $4 \%$ Oil & $6 \%$ Oil & $4 \%$ Oil & $6 \%$ Oil \\
\hline \multicolumn{6}{|l|}{ Grain Size } \\
\hline Sand, \% & 3.3 & 6.6 & 10.4 & 3.5 & 3.7 \\
\hline Silt, \% & 70 & 75.0 & 76.9 & 72.1 & 74.5 \\
\hline Clay, $\%$ & 26.7 & 17.5 & 11.4 & 24.4 & 22.8 \\
\hline Specific Gravity & 2.64 & 2.51 & 2.46 & 2.62 & 2.60 \\
\hline \multicolumn{6}{|l|}{ Consistency Limits } \\
\hline Liquid limit, \% & 61 & 66 & 68 & 62 & 64 \\
\hline Plastic Limit, \% & 27 & 29 & 28 & 25 & 29 \\
\hline Plasticity Index & 34 & 37 & 40 & 37 & 35 \\
\hline \multicolumn{6}{|l|}{ Compaction Characteristics } \\
\hline Optimum Moisture Content, \% & 20.5 & 16.4 & 15.0 & 18.7 & 17.8 \\
\hline Maximum Dry Density, kN/m ${ }^{3}$ & 14.7 & 15.2 & 14.8 & 14.9 & 14.5 \\
\hline $\begin{array}{l}\text { Coefficient Of Permeability } \\
\left(\times 10^{-8}\right) \mathrm{m} / \mathrm{s}\end{array}$ & 4.46 & 4.86 & 5.37 & 4.18 & 4.27 \\
\hline \multicolumn{6}{|l|}{ Consolidation Characteristics } \\
\hline Compression Index & 0.32 & 0.39 & 0.41 & 0.34 & 0.37 \\
\hline $\begin{array}{l}\text { Coefficient of consolidation } \\
\left(\times 10^{-8}\right) \mathrm{m}^{2} / \mathrm{s}\end{array}$ & 1.44 & 1.09 & 1.05 & 1.34 & 1.29 \\
\hline $\begin{array}{l}\text { Unconfined Shear Strength, } \\
\mathrm{kN} / \mathrm{m}^{2}\end{array}$ & 137.0 & 99.5 & 85.8 & 121.5 & 114.0 \\
\hline
\end{tabular}


It can be seen that the soil properties have undergone moderate to large modifications on account of the presence of lubricant oil. The grain-size distribution has changed as the soil became coarser with a large increase in the sand size, a moderate increase in the silt size, both of which can be account for the substantial decrease in clay size. Appreciable particles aggregation and change to coarse soil like behaviour in oil contaminated fine-grained soils has been reported $^{11}$ as a result of oil mixing. Specific gravity of the soil has also decreased and more at higher percentage of the oil. Liquid limits have increased too, whereas the plastic limits were also found to increase, albeit, nominally. The optimum moisture content registered substantial decrease, whereas maximum dry density first increased then decreased at higher oil percent. Coefficient of permeability increased at both the oil percentages. Compression index values also increased while coefficient of consolidation values decreased. The soil has lost substantial shear strength due to mixing with the lubricant oil. Other works ${ }^{16}$ have reported reduction in strength and permeability and increase in compressibility of Kuwaiti sand due to oil contamination. Drastic changes in soil properties have been reported ${ }^{17}$ due to contamination of fuel oil on soils near petrochemical complex in Vadodara, Gujrat, India. In a recent study modifications in settlement characteristics (compression index and coefficient of consolidation) of petroleum contaminated fine-grained soils have been found by investigators ${ }^{18}$.

Table 2 also shows the extent to which the properties of soil could be restored on washing with the surfactant in decontamination process. Figure 3 shows graphically both the impact of lubricant oil on various soil properties when compared to properties of virgin soil and percentage of recovery of soil properties after washing with surfactant again in relation to properties of virgin soil.

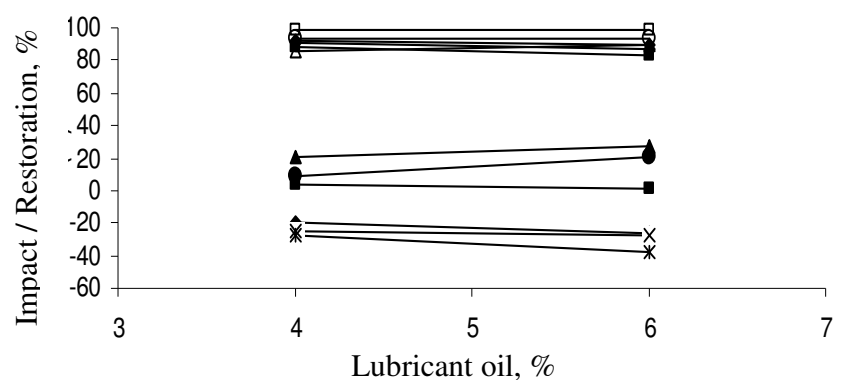

Figure 3. Contaminnat Impact and Restoration of Properties.

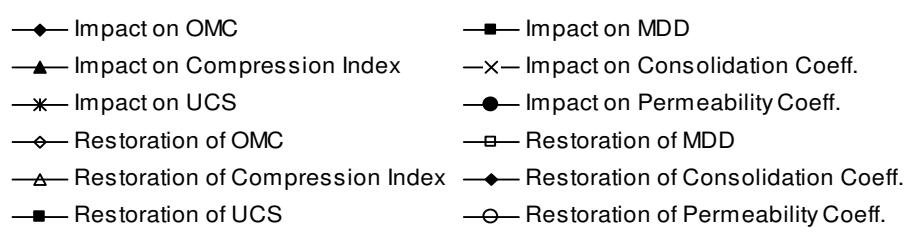

With regard to the particle size distribution of contaminated soil, the recovery in sand size was $94 \%$ to $88 \%$ respectively for $4 \%$ and $6 \%$ contamination, $97 \%$ and $94 \%$ for silt size and $91 \%$ to $85 \%$ in clay size. Specific gravity was restored by $92 \%$ to $85 \%$; liquid limit by $98 \%$ to $95 \%$ and plastic limit between $93 \%$ and $92 \%$. Optimum moisture content of the soil was restored by $91 \%$ to $87 \%$ and maximum dry density recovered by close to $99 \%$. Permeability values for both the contaminant percentages were restored by $94 \%$. For Compression index values, the recovery was $94 \%$ to $85 \%$, whereas coefficient of consolidation recovered from $90 \%$ to $85 \%$. The unconfined shear strength of the soil was restored from 
$89 \%$ to $83 \%$. Percentage restoration of contaminated soil vis-à-vis the virgin soil for various properties was thus varied from $83 \%$ to approximately $99 \%$. For higher percentage of oil the restoration in properties was obviously less as compared to the lower percentage of oil.

\section{Conclusions}

- Sorption experiments were two-step process with initial reaction being very fast followed by a slow reaction. Most of the sorption of cadmium took place in the first two hours from the start of reaction.

- Desorption process was the reverse of sorption process, however a little bit slower in comparison. Surfactant SDS was moderately effective in desorbing cadmium from the contaminated soil matrix.

- The physical and geotechnical properties of soil underwent modifications due to mixing with engine lubricant oil from moderate to substantial degrees.

- In decontamination experiments, the surfactant Triton X-100 was able to remove lubricant oil from the contaminated soil matrix substantially which is proven by very good restoration of soil properties vis-à-vis the virgin soil.

\section{References}

1. U S. EPA., Risk Assessment Guidelines, EPA 600-8-87-045, US Environmental Protection Agency, Washington, D C., 2003.

2. Evans H E., Effects of Dissolved Organic Carbon on the Behavior of PCBs in Fresh Waters, Doctoral Thesis, University of Toronto, 1991.

3. U S. EPA, Completed North American Innovative Remediation Technology Demonstration Projects, EPA-542-B-96-002, PB96-153-127, U.S. Environmental Protection Agency, Office of Solid Waste and Emergency Response, Washington D C., 1996.

4. Rosen M J, Surfactant and Interfacial Phenomenon; $2^{\text {nd }}$ Ed., Wiley Interscience: New York, 1989.

5. Al-Tabbaa A and Walsh S, Geotechnical Properties of a Clay Contaminated with an Organic Chemical, 1st International Congress on Environmental Geotechnics; Edmonton, Alberta, Canada, 1994, 599-604.

6. Jafvert C T, Van Hoof P L and Heath J K, Water Res., 1994, 28(5), 1009-1017.

7. Dwarkanath V, Rouse B A, Pope, G A. Kostarelos D, Shotts D and Wade W A, J Contam Hydrol., 1999, 38, 465-488.

8. Doong R, Lei W, Chen T, Lee C, Chen J and Cheng W, Water Sci Technol., 1996, 34, 327-334.

9. Hong P K A, Li C, Banerji S K and Regmi T, J Soil Contam., 1999, 8, 81-103.

10. Chu K H and Hashim M A, Acta Biotechnol., 2001, 21, 295-306.

11. Meegoda N J and Ratanveera P, Geotech Test J., 1995, 18(1), 41-49.

12. IS: 2720- Part 7 (BIS, 1974), Determination of Water Content- Dry Density Relation Using Light Compaction.

13. Hsi C K D and Langmuir D, Geochim Cosmochim Acta, 1986, 49, 1931-1941.

14. Waite T D, Davis J A, Payne T E, Waychunas G A and Xu N, Geochim Cosmochim Acta, 1994, 58, 5465-5478.

15. Sparks D L, Environmental Soil Chemistry; Academic Press, Inc., California, 1995, 268.

16. Al-Sanad H A, Eid W K and Ismael N F, J Geotech Eng., ASCE, 1995, 121, 407- 416.

17. Shah S J, Shroff A V, Patel J V, Tiwari K C and Ramkrishnan D, Geotech Geol Eng 2003, 21(4), 415-427.

18. Singh A K, Srivastava R K and John S, Soil Sediment Contam., 2008, 17, 290-300. 


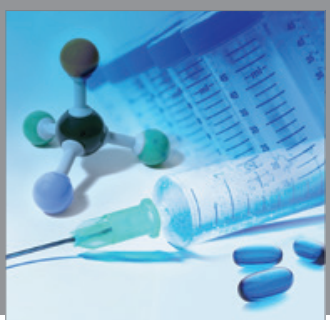

International Journal of

Medicinal Chemistry

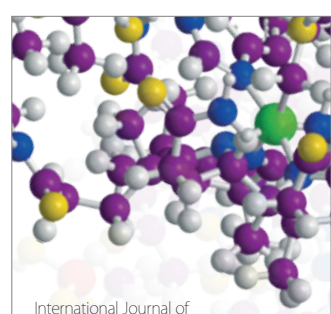

Carbohydrate Chemistry

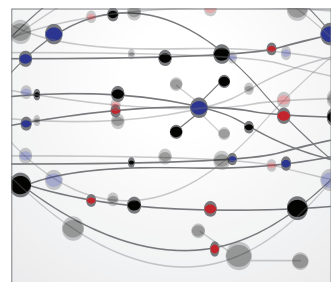

The Scientific World Journal
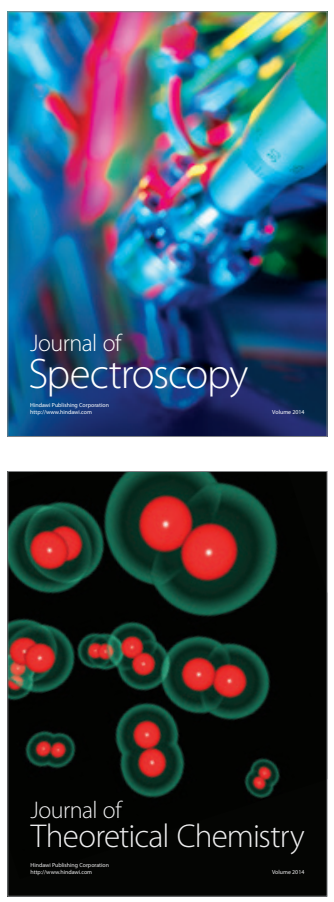
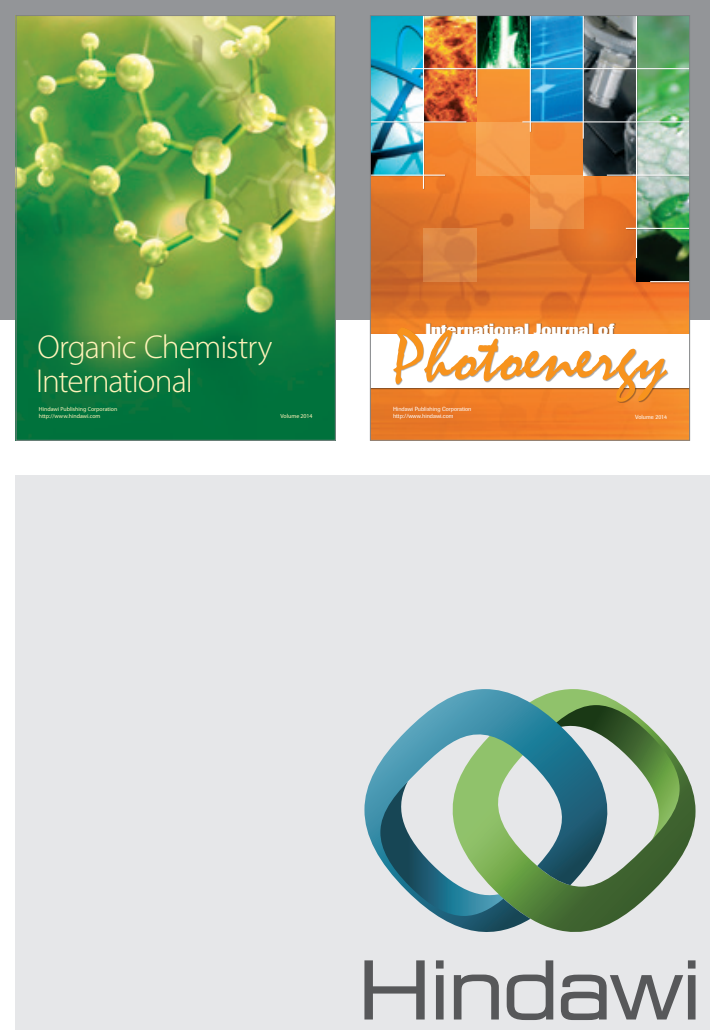

Submit your manuscripts at

http://www.hindawi.com
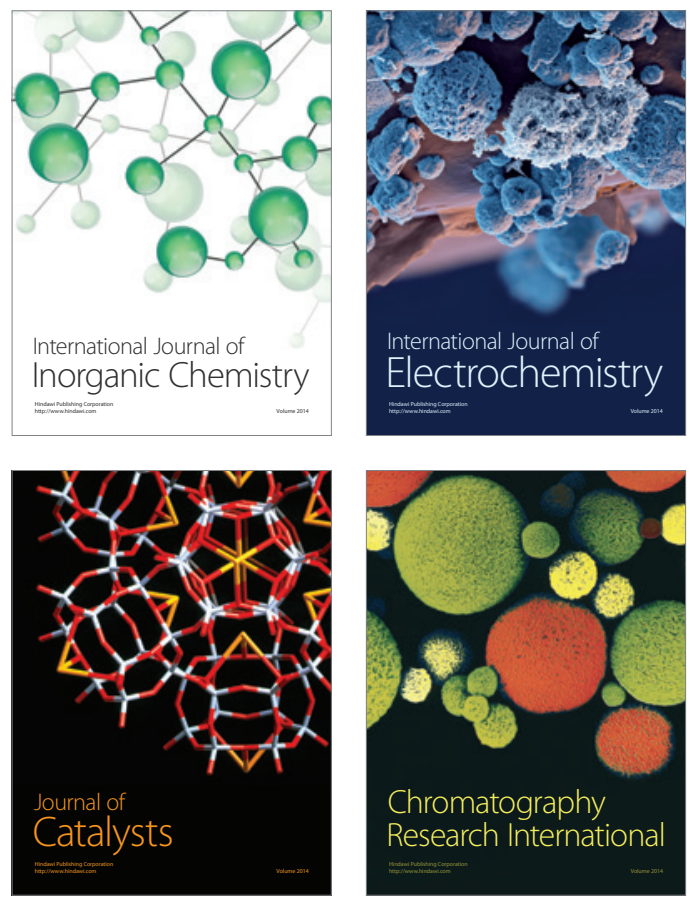
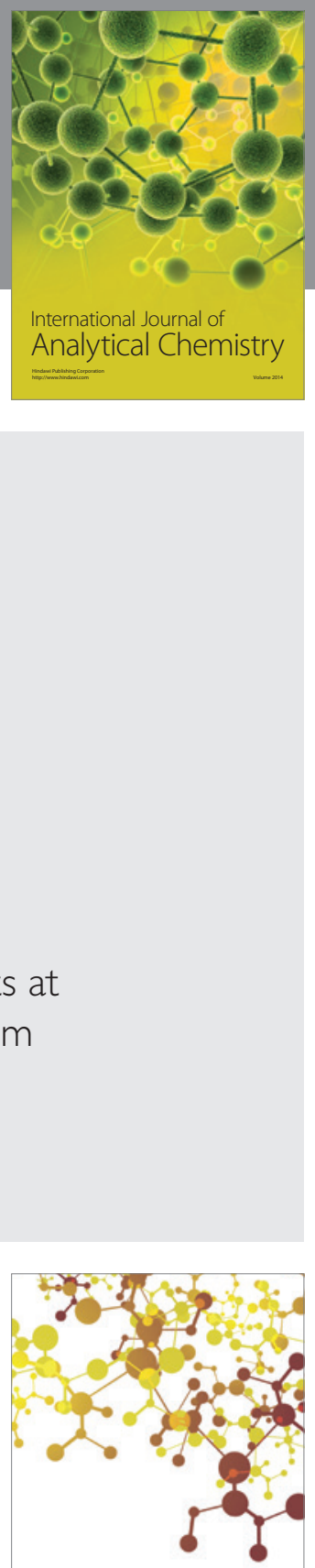

Journal of

Applied Chemistry
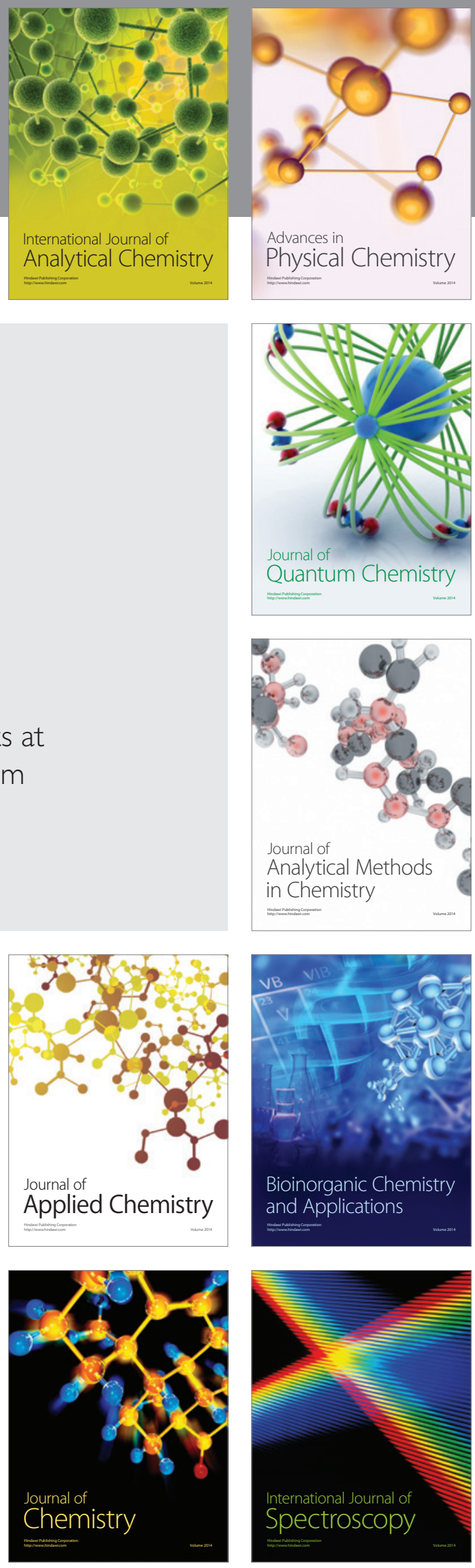